\title{
OPEN Evaluation of airborne total suspended particulates and heavy metals in anodizing and electroplating surface treatment process
}

\author{
Donghyeon $\mathrm{Kim}^{1}$, Sungyo Jung ${ }^{2} \&$ Chungsik Yoon ${ }^{1,2 \varpi}$
}

This study is to evaluate exposure to harmful substances, such as particulate and heavy metals, by considering various factors, in anodizing and electroplating surface treatment process. Exposure evaluation studies on seven heavy metals $(\mathrm{Cr}, \mathrm{Zn}, \mathrm{Ni}, \mathrm{Pb}, \mathrm{Cd}, \mathrm{Al}$, and $\mathrm{Ba})$ and total suspended particulates (TSP) were conducted. Heavy metals were analyzed using inductively coupled plasma mass spectrometry (ICP-MS). This study also checked the ventilation volume of the hood with a thermal anemometer. Measurement was conducted for $8 \mathrm{~h}$ and 8 days. The sample number, $\mathrm{N}$, of the heavy metals and TSP was 107. Geometric mean (GM) of TSP during Cr plating process was 6.15(GSD, 3.35) $\mathrm{mg} / \mathrm{m}^{3}$. GM of Cr during Cr plating was $1.86(\mathrm{GSD}, 6.65) \mathrm{mg} / \mathrm{m}^{3}$. GM of TSP and heavy metals differences were statistically significant for each process and date variation. Average ventilation volume for all hoods ranged from 1.20 to $4.98 \mathrm{~m}^{3} / \mathrm{s}$. In the hood $30 \mathrm{~cm}$ from bath, ventilation was 0.1 times lower. Increasing ventilation volume of the hood was the most influential factor, followed by machine operation time and workload. The high concentration was due to low ventilation suction flow. We can improve health to reduce exposure by resolving the fundamental cause of risk occurrence.

Among the metal material industry, the surface treatment industry improves the product quality of protective surfaces by using electrical, physical, and chemical treatment methods on two surface materials to prevent rust, beautify appearance, and increase wear resistance, electrical insulation, and electrical conductivity ${ }^{1}$.

As anodizing, the cathode is made of $\mathrm{Al}$ alloy, $\mathrm{Pb}$, or stainless steel. Anodizing is applied to improve corrosion by an anode + oxidizing, thereby undergoing degreasing, neutralization as a pre-treatment process, coloring, sealing, polishing, and non-polishing as a post-treatment process. The oxide film is formed by soft anodizing and hard anodizing. As a post-treatment process, the product is completed through neutralization, water cleaning, drying, and packaging ${ }^{2}$.

The most important exposed materials in the anodizing process are heavy metals. During the process of oxide film formation, abundant $\mathrm{Al}$ depending on the type of $\mathrm{Al}$ alloy are used, and exposure to other heavy metals is possible. The artificial exposure route of $\mathrm{Al}$ is through the respiratory tract, $\mathrm{Al}$ is related to potroom asthma, chronic bronchitis, pulmonary fibroids, and granulomatous lung diseases upon exposure through inhalation ${ }^{3}$. $\mathrm{Al}$ exposure was significantly correlated with various neurological disorders, and contact dermatitis in workers exposed to $\mathrm{Al}$ alloy and $\mathrm{Al}$ dust also has been reported. Al toxicity can occur as a result of the interaction between $\mathrm{Al}$ and the plasma membrane with target established by the body ${ }^{4}$. $\mathrm{Al}$ inhaled through the respiratory tract is replaced by magnesium and iron, resulting in intercellular exchange, cell growth, and secretion functions. The changes in neurons by $\mathrm{Al}$ are similar to the degenerative lesions observed in Alzheimer's patients, and complication of $\mathrm{Al}$ toxicity may have neurotoxic effects, such as nerve atrophy of the cerebellum, black matter, and striatum ${ }^{5}$. Similarly, high concentrations of $\mathrm{Al}$ are very toxic to aquatic animals, especially gill-respiring organisms such as fish, and can destroy plasma and bloodstream ions, and cause osmotic disorders ${ }^{6}$.

Chromium plating was used by an electrolytic solution of chromic acid during the plating process. Workers can be exposed to Hexavalent chromium (Cr (VI)) during the mixing of acid powders and carrying products ${ }^{7}$.

${ }^{1}$ Institute of Health and Environment, Seoul National University, Seoul, South Korea. ${ }^{2}$ Department of Environmental Health Sciences, Graduate School of Public Health, Seoul National University, Seoul, South Korea. ${ }^{\circledR}$ email: csyoon@snu.ac.kr 


\begin{tabular}{|c|c|c|c|}
\hline & Temperature $\left({ }^{\circ} \mathrm{C}\right)$ & Operation $(\mathrm{sec})^{\mathrm{a}}$ & Electrolyte composition (chemical) \\
\hline Degreasing & $45-55$ & $30-90$ & $\mathrm{Na}_{2} \mathrm{CO}_{3}, \mathrm{Na}_{3} \mathrm{PO}_{4}, \mathrm{NaC}_{2} \mathrm{HCl}_{3}, \mathrm{C}_{2} \mathrm{Cl}_{4}$ \\
\hline Etching \& Neutralization & $55-65$ & $30-60$ & $\mathrm{NaOH}, \mathrm{H}_{2} \mathrm{SO}_{4}, \mathrm{HF}, \mathrm{HNO}_{3}$ \\
\hline Soft anodizing_ $1^{\star}$ & $21-27$ & $2,400-2,700$ & $\mathrm{H}_{2} \mathrm{SO}_{4}, \mathrm{Al}_{2} \mathrm{O}_{3}$ \\
\hline Soft anodizing_ $2^{* *}$ & $21-27$ & $2,400-2,700$ & $\mathrm{H}_{2} \mathrm{SO}_{4}, \mathrm{Al}_{2} \mathrm{O}_{3}$ \\
\hline Hard anodizing_1* & $-4-4$ & $312-432$ & $\mathrm{H}_{2} \mathrm{SO}_{4}, \mathrm{Al}_{2} \mathrm{O}_{3}$ \\
\hline Hard anodizing_ $2^{* *}$ & $-4-4$ & $312-432$ & $\mathrm{H}_{2} \mathrm{SO}_{4}, \mathrm{Al}_{2} \mathrm{O}_{3}$ \\
\hline Chromium plating & $65-75$ & $600-720$ & $\mathrm{H}_{2} \mathrm{SO}_{4}, \mathrm{H}_{2} \mathrm{CrO}_{4}$ \\
\hline Coloring $1^{*}$ & $40-60$ & $600-720$ & Azo \\
\hline Coloring $2^{* *}$ & $40-60$ & $600-720$ & Azo \\
\hline Sealing & $65-75$ & $420-780$ & $\mathrm{C}_{2} \mathrm{H}_{3} \mathrm{NaO}_{2}(12 \%), \mathrm{Ni}\left(\mathrm{CH}_{3} \mathrm{CO}_{2}\right)_{2}(5 \%)$ \\
\hline Polishing & $100-120$ & $60-180$ & $\mathrm{H}_{2} \mathrm{SO}_{4}, \mathrm{HNO}_{3}, \mathrm{Al}_{2} \mathrm{O}_{3}, \mathrm{H}_{2} \mathrm{CrO}_{4}$ \\
\hline Non-polishing & $45-55$ & $60-90$ & $\mathrm{H}_{2} \mathrm{SO}_{4}, \mathrm{HNO}_{3}, \mathrm{Al}_{2} \mathrm{O}_{3}, \mathrm{H}_{2} \mathrm{CrO}_{4}$ \\
\hline Chromium cleaning & $21-27$ & $180-300$ & $\mathrm{CH}_{2} \mathrm{Cl}_{2}$ \\
\hline
\end{tabular}

Table 1. Temperature, operation time and used chemical in all the processes. ${ }^{\star} 1=$ Medium size of bath. ${ }^{* *} 2=$ Large size of bath. ${ }^{\text {a Time }}$ (second) to make 1 product.

Hexavalent chromium (Cr (VI)) compounds are occupational carcinogens that cause lung, nasal, and sinus cancers $^{8-10}$. Cr (VI) compounds are produced from other airborne forms of $\mathrm{Cr}$ industries that use $\mathrm{Cr}$ (VI) compounds, such as steel passivation, electroplating, stainless steel welding, and paints production, Cr-based pigments, fungicides, and anti-corrosion compounds as a by-product ${ }^{11}$. Exposure to Cr during electroplating is a characteristic cause of occupational asthma. Sensitivity to $\mathrm{Cr}$ in electroplates may occur in situations where exposure levels are likely to be within the current exposure standards ${ }^{12}$.

Previous similar studies on plating show that the metal surface is plated by shooting electrons from the cathode (Eq. $\left.1 ;{ }^{13}\right)$. For anodizing, the surface treatment principle is different; the surface of the metals is anodized by shooting oxygen from the anode ${ }^{14}$. The reactions occur simultaneously during anodizing ${ }^{3}$ (Eqs. 2, 3).

-plating equation.

$$
\mathrm{M}^{\mathrm{n}+}+\mathrm{ne}^{-} \rightarrow \mathrm{M}^{\mathrm{o}}
$$

where $\mathrm{M}^{\mathrm{n}+}$ is ion, $\mathrm{n}$ is number of moles reacting, and $\mathrm{e}^{-}$is electron and $\mathrm{M}^{\mathrm{o}}$ is the metals.

-anodizing equation (oxidation and dissolution).

$$
\begin{gathered}
2 \mathrm{Al}+3 \mathrm{H}_{2} \mathrm{O} \rightarrow \mathrm{Al}_{2} \mathrm{O}_{3}+6 \mathrm{H}^{+}+6 \mathrm{e}^{-} \\
\mathrm{Al}_{2} \mathrm{O}_{3}+6 \mathrm{H}^{+} \rightarrow 2 \mathrm{Al}^{3+}+3 \mathrm{H}_{2} \mathrm{O}
\end{gathered}
$$

This study evaluated the exposure of each process of business sites performing $\mathrm{Al}$ anodizing and $\mathrm{Cr}$ electroplating. Exposure evaluation studies on seven heavy metals ( $\mathrm{Cr}, \mathrm{Zn}, \mathrm{Ni}, \mathrm{Pb}, \mathrm{Cd}, \mathrm{Al}$, and $\mathrm{Ba}$ ) and TSP were conducted. This study also evaluated harmful substances by checking the ventilation volume of the hoods. The sample number, N, for TSP and heavy metals is 107 .

\section{Materials and methods}

Table 1 shows the temperature, operations time, and electrolyte chemical composition of the bath in all the workplace processes. There are three standard surface treatment baths at this workplace which were used; the number 1 represents the medium-sized bath, and the number 2 represents the large-sized bath. Table S1 lists the values for special processes that require specific $\mathrm{pH}$ or voltage adjustments and provides information on temperature and humidity during the working environment measurement period. Table S2 shows the amount of work and the number of workers during the work environment measurement period, which can be important factors for identifying variable factors according to concentration.

The workplace in this study addressed all processes for anodizing and $\mathrm{Cr}$ plating, and the processes can be largely divided into pre-treatment, anodizing, Cr plating, and post-treatment processes. There are three types of surface treatment baths: small, medium and large. But small baths are rarely used in the process. So, to reflect realistic exposure, medium and large baths were evaluated except for small baths (Fig. 1). Drying, packaging, and assembling processes are connected to the above processes (Figure S1).

Samples were collected at a height of $1.5 \mathrm{~m}$ to represent the breathing zone of workers. The measurement time proceeded from $8: 30$ am to 5:30 pm for 8 days, and the measurement was conducted for total of $8 \mathrm{~h}$, excluding breaktime. As a control, the anodizing and plating control sample and drying and packaging control sample were placed in the workplace to check the blank.

Air sampling and analysis of TSP. PVC (Polyvinyl Chloride) filter ( $37 \mathrm{~mm}$, pore size $5 \mathrm{um}, \mathrm{SKC}$, USA) in the three-piece $37 \mathrm{~mm}$ closed face plastic cassette (Whatman Grade QM-A, $37 \mathrm{~mm}$; Whatman, Maidstone, UK) was used to measure fine dust generated during the operation of forming an oxide film and plating, which 


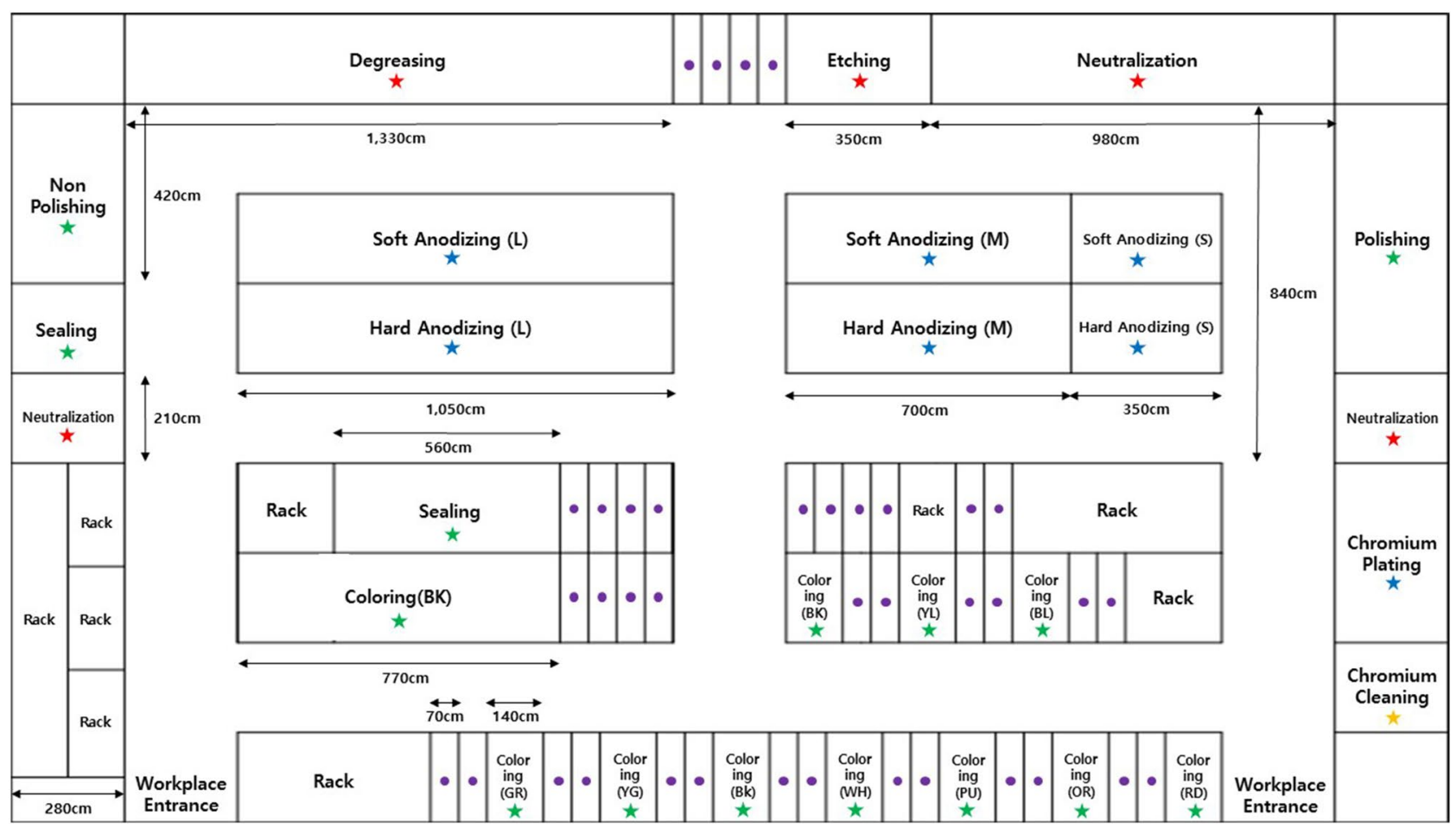

Figure 1. Anodizing and Electroplating schematic and sample location 1: the icons are the sampling locations (red star: pre-treatment process, blue star: anodizing and electroplating process, green star: post-treatment process, orange star: other processes, purple circle: cleaning process). RD Red, OR Orange, YL Yellow, GR Green, $B L$ Blue, $P U$ Purple, YG Yellow Green, $W H$ White. Workplace $(35 \mathrm{~m} \times 17.85 \mathrm{~m})$.

were the main processes during anodizing and electroplating. These were connected by two types of air sampling pump (Casella APEX-2, USA \& Gillian, USA) operating at an airflow rate of $2 \ell / \mathrm{min}$. The sample was wrapped with Parafilm (Bemis Company, USA) before and after the sample was collected so as not to be exposed to outside air and then stored to room temperature.

To analyze the TSP, PVC filter was contained in a desiccator for more than $24 \mathrm{~h}$, and then weighed using an analytical balance having $0.01 \mu \mathrm{g}$ sensitivity (Mettler XP6 Microbalance, Mettler Toledo, Hightstown NJ, USA). Before measuring weight of the filter, static electricity was removed and weight change according to daily temperature and humidity change was corrected using a blank filter. Weight was measured 3 times per sample, and the average value was used as the final weight concentration. High flow rate pump was calibrated before and after sampling using a flow calibrator (Drycal, Defender 520-M, MesaLabs, USA).

Air sampling and analysis of heavy metals. The air sampling and analysis of heavy metals were based on the NIOSH method $7300^{15}$. After the weighing TSP, the remaining was also used to measure heavy metals, as described for TSP measurement. After sampling, PVC filter was folded four times into a microwave vessel, and then $4 \mathrm{ml}$ of 70\% nitric acid solution (Sigma Aldrich, MO, USA) was added. Samples were extracted using a PVC filter and PC(Polycarbonate) filter method stored in a library in a microwave (Model: MARS 6, CEM Corp., Matthews, NC, USA) for 2 times. The temperature was gradually raised to $200{ }^{\circ} \mathrm{C}$ for $20 \mathrm{~min}$ and then maintained for $20 \mathrm{~min}$. The pressure was set to $800 \mathrm{psi}$, and the power to $900-1050 \mathrm{~W}$. After this process, the vessel was cooled in the microwave for $20 \mathrm{~min}$ and at room temperature for $50 \mathrm{~min}$. The extracted sample was diluted to $40 \mathrm{ml}$ with $1 \%$ nitric acid solution, and quantitative analysis was performed using an inductively coupled plasma mass spectrometer (ICP-MS, Model: NexION 350D, Perkin Elmer Inc., Houston, TX, USA). The conditions show under the Table S3.

Quality controls (QC). Quality assurance and Quality controls (QA/QC) for heavy metals was performed. LODs of heavy metals was determined by triple standard deviations from seven replicates at the lowest level of the standard solution ( 1 to $20 \mu \mathrm{g} / \mathrm{L}$ ), and a determination coefficient $\left(\mathrm{r}^{2}\right)$ was more than 0.99 and it showed the linearity ${ }^{16}$. The values are Cr 0.003, Mn 0.019, Co 0.003, Zn 0.017, Ni 0.013, Ag 0.014, Pb 0.006. Cd 0.008, Fe 0.005, Al 0.004, Ba 0.002, As 0.034, Sr 0.013, Na 0.004, Mg 0.032, Cu 0.010, K 0.037 $\mu \mathrm{g} / \mathrm{sample.}$

Hood ventilation measurement. A thermal anemometer (TSI 9515, VelociCheck, TSI, USA) was used to measure the hood characteristics, ventilation volume $\left(\mathrm{m}^{3} / \mathrm{s}\right)$, and wind speed $(\mathrm{m} / \mathrm{s})$ according to distance. There are two types of thermal anemometers (one-way directional and omni-directional); this study used a one-way type. Figure S2 shows the overall shape of the hood; the workplace contained small, medium, and large hoods. Sampling and ventilation volume were measured at the medium and large hoods. The number 1 and 2 


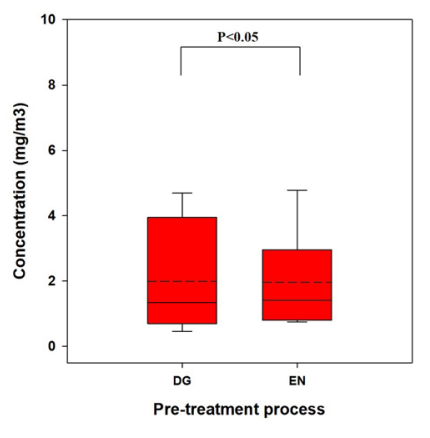

TSP

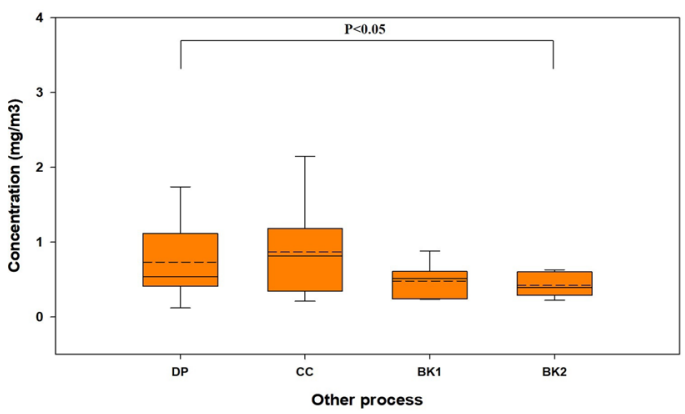

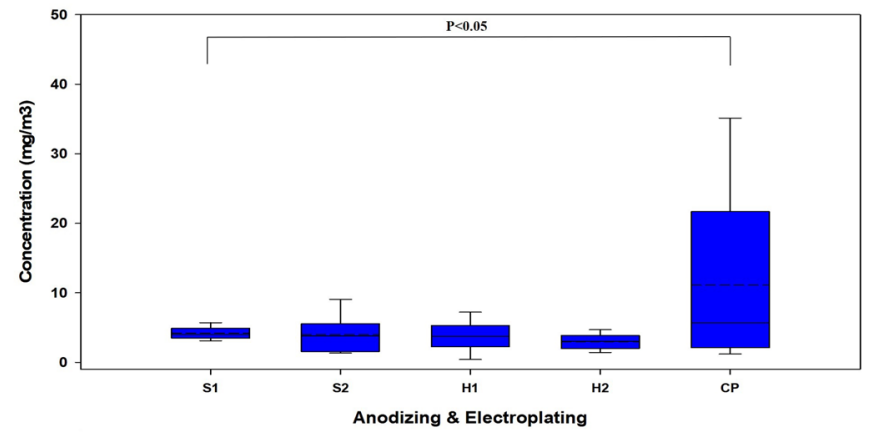

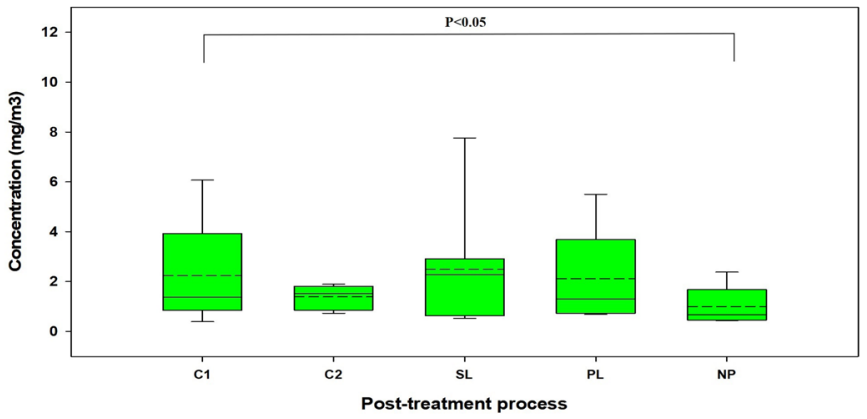

Figure 2. Bar plots of the TSP concentration air in all the processes. The TSP concentrations are arithmetic means. Values are median (line within box), mean (dotted line within box), 5th and 95th percentiles (bottom and top of box, respectively), minimum (lower bars on whisker), maximum (upper bars on whisker). $D G$ Degreasing, EN Etching \& Neutralization, S1 Soft Anodizing_1, S2 Soft Anodizing_2, H1 Hard Anodizing_1, H2 Hard Anodizing_2, CP Chromium plating, C1 Coloring_1, C2 Coloring_2, SL Sealing, PL Polishing, NP Non polishing, DP Drying \& Packaging, CC Chromium cleaning, B1 Blank (Plating \& Anodizing), B2 Blank (Drying \& Packaging).

denotes medium and large hood, respectively. Five points on the hood were determined to measure ventilation and airflow. Point 1, 2 and 3 were controlled from the middle. Point 4 was controlled directly under the bath, and point 5 was measured for ventilation and airflow at a distance of $30 \mathrm{~cm}$ from the midpoint of points 1-4. The polishing process only had extra point.

Data analysis. Air sample concentrations were expressed in terms of arithmetic mean (AM), standard deviation (SD), geometric mean (GM), geometric standard deviation (GSD), and median and range (min-max). The Shapiro-Wilk test confirmed that the TSP and heavy metals were log-normally distributed. Measured air concentrations of TSP and heavy metals in each process were compared using analysis of variance (ANOVA), and the Bonferroni method was used for post-hoc analysis. The date variations for TSP and heavy metals in each process were compared using ANOVA. Multivariate multiple linear regression was performed to find factors that affect TSP and heavy metals concentration. Response variables were TSP and heavy metals, and explanatory variables were workload, number of workers, and amount of ventilation volume. $\mathrm{P}<0.05$ was considered statistically significant. Statistical analysis was performed using R software v.3.6.3. (R Development Core Team, Vienna, Austria). Graphs were plotted using Sigmaplot 14.0 (Systat software, Inc, USA).

\section{Results}

TSP. Table S4 and Table S5 show the TSP concentrations of all the process samples measured in the workplace. The highest GM concentrations of the samples were for Cr plating $\left(6.15(\mathrm{GSD}, 3.35) \mathrm{mg} / \mathrm{m}^{3}\right)$. As a result of ANOVA test, GM concentrations of every process were statistically significant, showing that the process samples have different exposure aspects during product creation. Differences in GM concentrations and daily variation were statistically significant among the anodizing and electroplating, post-treatment, pre-treatment, and other processes. For the pre-treatment process, the average TSP concentration of degreasing was similar to that of etching and neutralization; however, the range was much higher than that of etching and neutralization. Anodizing and electroplating have similar soft and hard anodizing aspects, whereas Cr electroplating has a much higher concentration than all the processes. During the post-treatment process, the average TSP concentration of sealing has the highest average, whereas coloring and polishing have a wide concentration range. In the "other" processes, the TSP average concentration was generally lower. However, the drying and packaging and $\mathrm{Cr}$ cleaning processes have sufficient concentrations (Fig. 2). 

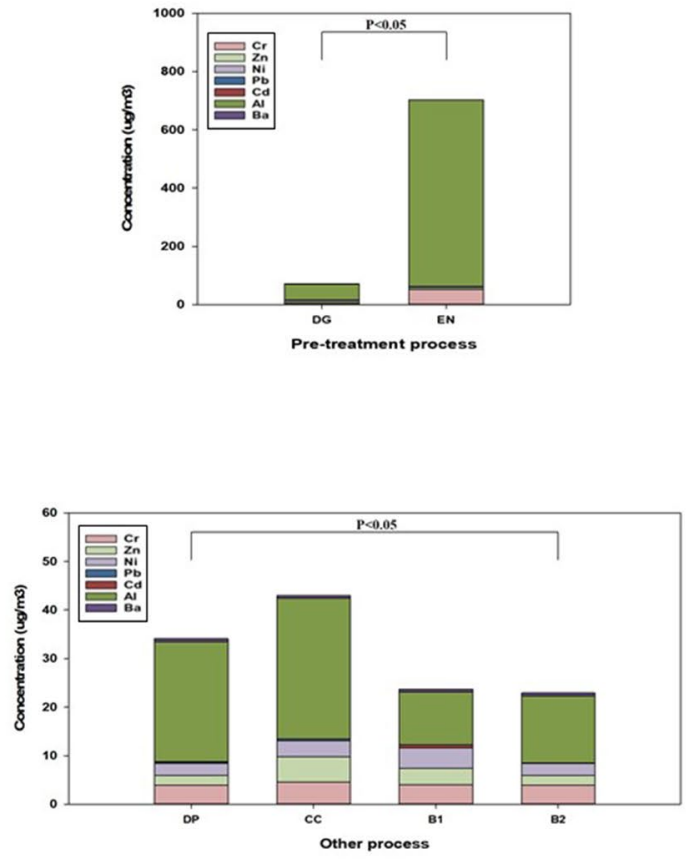
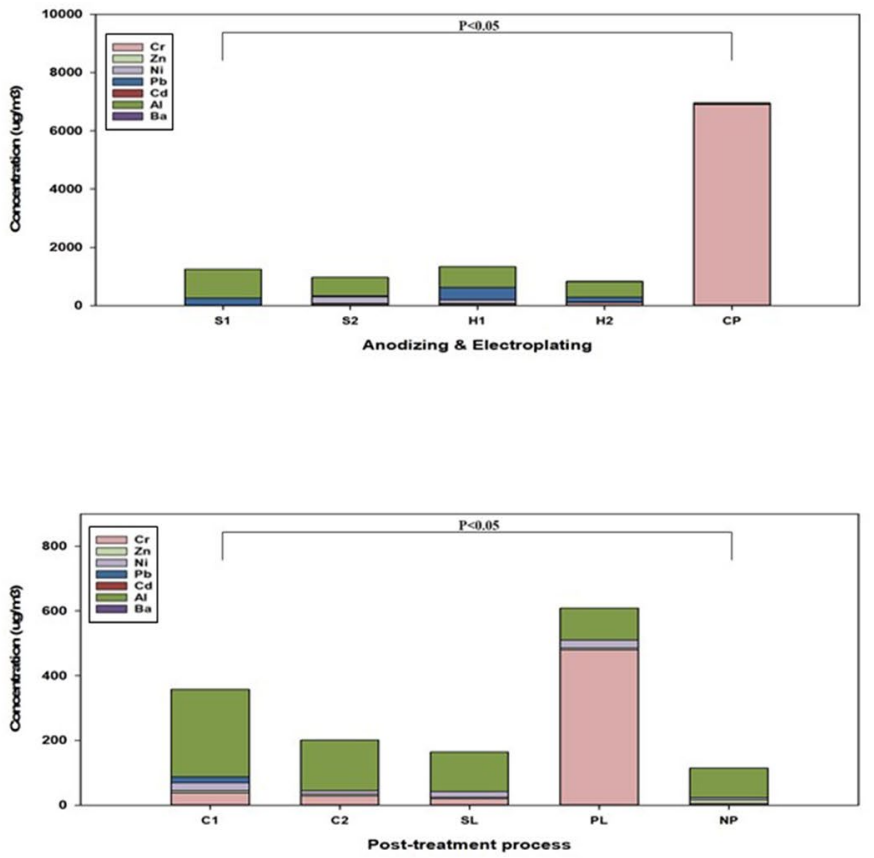

Figure 3. Heavy metals ratio in all the processes. The heavy metals concentrations are arithmetic means. There are a total of seven heavy metals. $\mathrm{Cr}$ Chromium, $\mathrm{Zn} \mathrm{Zinc}, \mathrm{Ni}$ Nickel, $\mathrm{Pb}$ Lead, $\mathrm{Cd}$ Cadmium, $\mathrm{Al}$ Aluminum, Ba Barium, DG Degreasing, EN Etching \& Neutralization, S1 Soft Anodizing_1, S2 Soft Anodizing_2, H1 Hard Anodizing_1, H2 Hard Anodizing_2, CP Chromium plating, C1 Coloring_1, C2 Coloring_2, SL Sealing, PL Polishing, NP Non polishing, DP Drying \& Packaging, CC Chromium cleaning, B1 Blank (Plating \& Anodizing), B2 Blank (Drying \& Packaging).

Heavy metals. The heavy metal totals were analyzed with 17 types, including the existing seven $(\mathrm{Cr}, \mathrm{Mn}$, $\mathrm{Zn}, \mathrm{Ni}, \mathrm{Pb}, \mathrm{Cd}, \mathrm{Al}$, and Ba) types and ten other types. Table S6, Table S7, Table S8, Table S9, Table S10, Table S11, Table S12 and Table S13 show the exposure to seven types of heavy metals in all workplace processes. GM of Cr during Cr plating was $1,859.66(6.65) \mu \mathrm{g} / \mathrm{m}^{3}$. GM of $\mathrm{Cr}$ during medium-sized soft anodizing, large-sized soft anodizing, medium-sized hard anodizing and large-sized hard anodizing were 52.94(17.71), 4.85(7.96), $151.40(11.09)$ and $85.52(4.82) \mu \mathrm{g} / \mathrm{m}^{3}$, respectively. $\mathrm{Pb}$ during $\mathrm{Cr}$ plating was $1.13(3.61) \mu \mathrm{g} / \mathrm{m}^{3}$. Al concentrations were high in most processes. GM of Al during medium-sized soft anodizing, large-sized soft anodizing, medium-sized hard anodizing, and large-sized hard anodizing were 528.97(6.80), 553.31(1.81), 545.98(2.75), and $520.79(1.34) \mu \mathrm{g} / \mathrm{m}^{3}$, respectively. Differences in GM concentrations and daily variation of the GMs of heavy metals were statistically significant. When the proportion of heavy metals was confirmed, the analysis was performed with seven basic heavy metals, excluding the 10 other heavy metals. Pre-treatment processes confirmed that $\mathrm{Al}$ occupied the largest proportion of heavy metals, followed by $\mathrm{Cr}$, and occupied most of the anodizing and electroplating processes; for $\mathrm{Cr}$ plating, however, $\mathrm{Cr}$ occupied the largest proportion. The post-treatment process revealed that the $\mathrm{Cr}$ concentration occupied a high rate while polishing. In other processes, $\mathrm{Al}$ occupied the highest rate, and Ni occupied the highest rate in the drying and packaging processes (Fig. 3).

Relationship between TSP and heavy metals. Figure 4 shows the correlation distribution between TSP and heavy metals $(\mathrm{N}=107)$ concentrations. The coefficient of determination $\mathrm{r}^{2}$ was 0.994 , indicating a strong relationship. The ratio of seven kinds of heavy metals causing adverse health effects relative to the total measured substances in the air was not relatively high. The $\mathrm{Cr}$ concentration accounted for $62.65 \%$ in degreasing, drying and packaging, and $\mathrm{Cr}$ cleaning and for $20-40 \%$ in soft and hard anodizing (Fig. 5).

Ventilation. The workplace was equipped with a hood for every process, and the total suction flow rate for all the processes was $600 \mathrm{~m}^{3} / \mathrm{s}$. The hood had a total of four slots, and the polishing process involved a total of five slots. Table S14 and Table S15 show the total ventilation volume for each slot in all the processes; the average ventilation volume for all hoods ranged from $1.20-4.98 \mathrm{~m}^{3} / \mathrm{s}$. Slot 3 is designed to have the highest ventilation volume of the hood, and slot 4 is designed to be the next highest, with suction directly below. For the pretreatment process, the average degreasing $\left(1.74 \mathrm{~m}^{3} / \mathrm{s}\right)$ and etching \& neutralization $\left(1.77 \mathrm{~m}^{3} / \mathrm{s}\right)$ were ventilated. For anodizing and electroplating, medium-sized soft anodizing was $1.76 \mathrm{~m}^{3} / \mathrm{s}$, and large soft anodizing was 2.14 $\mathrm{m}^{3} / \mathrm{s}$. The medium-sized and large-sized hard anodizing had average ventilation volumes of 2.12 and $2.33 \mathrm{~m}^{3} / \mathrm{s}$, respectively. Ventilation volume for Cr plating was $2.94 \mathrm{~m}^{3} / \mathrm{s}$ and was the largest than in any other processes. For the post-treatment process, the medium-sized and large-sized colorings are 1.22 and $1.31 \mathrm{~m}^{3} / \mathrm{s}$, respectively. The ventilation of the hood $30 \mathrm{~cm}$ away from the bath was very low. The $30 \mathrm{~cm}$ away inhalation volume was 0.1 times lower than the average ventilation volume. 


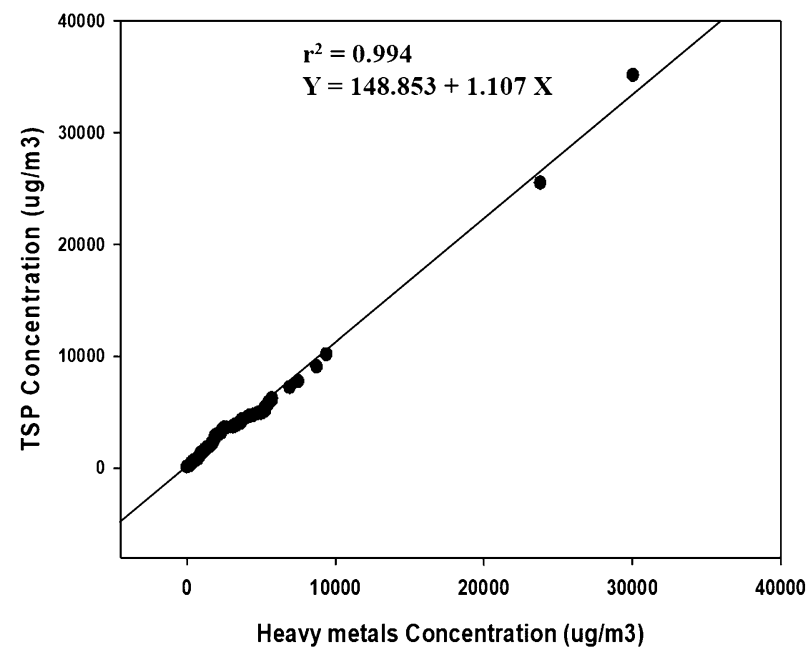

Figure 4. Distribution of heavy metals and TSP. All the concentrations are arithmetic means $(\mathrm{N}=107)$.
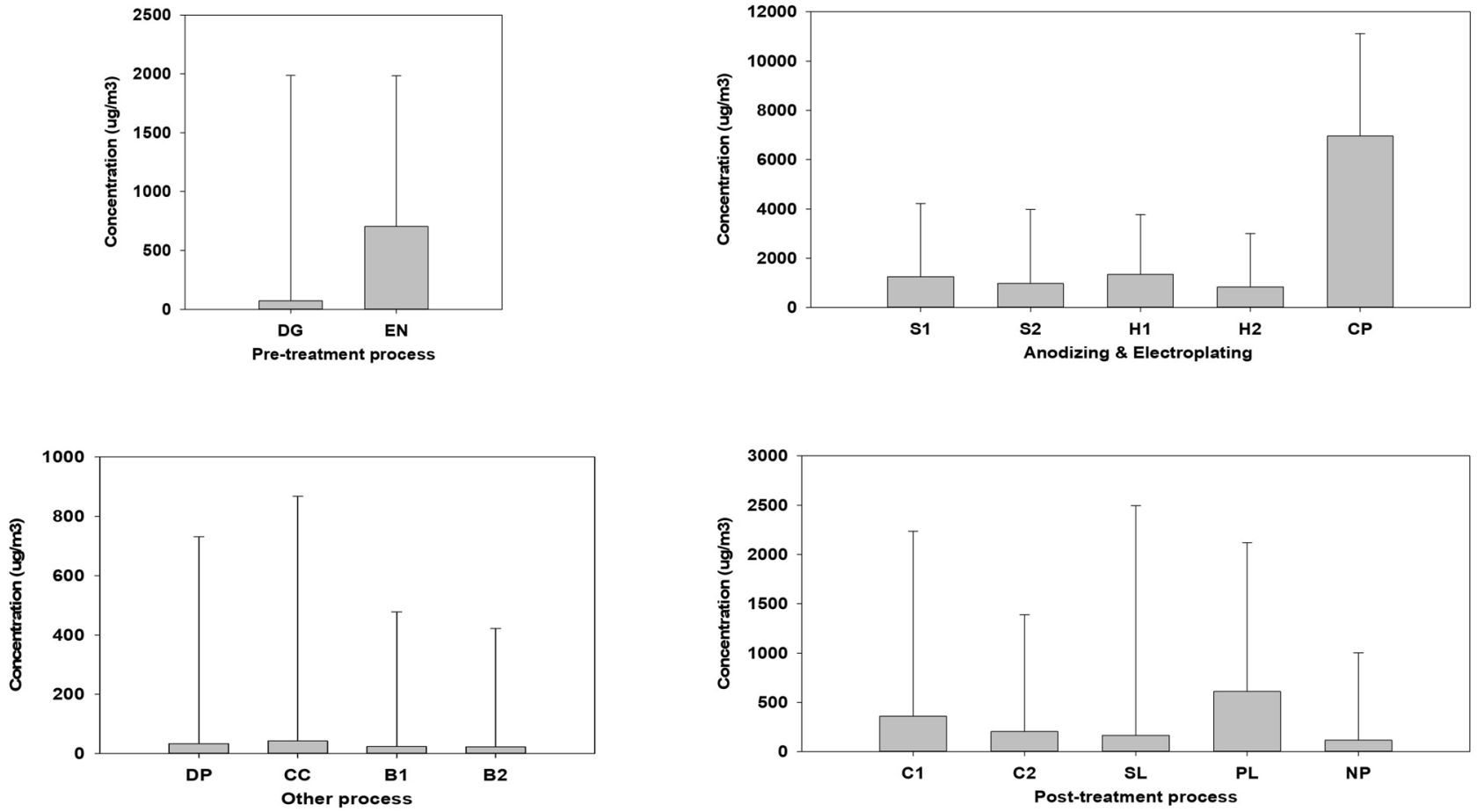

Figure 5. Ratio of heavy metals and other substances in all the processes. The heavy metals concentrations are arithmetic means for a total of seven heavy metals. Error bar denote other substances. DG Degreasing, EN Etching \& Neutralization, S1 Soft Anodizing_1, S2 Soft Anodizing_2, H1 Hard Anodizing_1, H2 Hard Anodizing_2, CP Chromium plating, C1 Coloring_1, C2 Coloring_2, SL Sealing, PL Polishing, NP Non polishing, DP Drying \& Packaging, CC Chromium cleaning, B1 Blank (Plating \& Anodizing), B2 Blank (Drying \& Packaging).

Regression analysis for TSP and heavy metals. Multiple linear regression analysis was conducted by setting TSP and heavy metals $(\mathrm{N}=107)$ as response variables, and environmental factors were expected to affect the concentrations of TSP and heavy metals in the workplace as explanatory variables (Table 2). Regression model of TSP analysis with three variates was statistically significant. Ventilation volume at a distance of $30 \mathrm{~cm}$ from the hood, machine operating time, and workload affected TSP concentrations. The most influential factor on TSP in the workplace was ventilation volume at a distance of $30 \mathrm{~cm}$ from the hood. TSP coefficient decreased by 0.94 as ventilation volume standard deviation (SD) 1 increased. TSP coefficient increased by 0.62 as machine operating time SD 1 increased. As workload SD 1 increased, TSP coefficient increased by 0.18 . From statistical 


\begin{tabular}{|c|c|c|c|c|c|c|c|c|}
\hline \multirow[b]{2}{*}{ Variables } & \multicolumn{4}{|l|}{ TSP } & \multicolumn{4}{|l|}{ Heavy metals } \\
\hline & R (Correlation) & $\beta^{* *}\left(\beta^{* * *}\right)$ & $t$-value * & $\mathbf{F}$ & R (Correlation) & $\beta^{* *}\left(\beta^{* * *}\right)$ & t-value * & $\mathbf{F}$ \\
\hline $\begin{array}{l}\text { Hood } 30 \mathrm{~cm} \text { dis- } \\
\text { tance ventilation }\end{array}$ & 0.49 & $\begin{array}{l}-0.94 \\
(-1,031.37)\end{array}$ & -4.55 & 22.31 & 0.38 & $-0.93(-930.34)$ & -4.51 & 20.78 \\
\hline $\begin{array}{l}\text { Machine opera- } \\
\text { tion time }\end{array}$ & 0.28 & $0.62(14.97)$ & 2.92 & 14.02 & 0.27 & $0.63(13.50)$ & 2.96 & 12.92 \\
\hline Workload & 0.11 & $0.18(13.44)$ & 2.05 & 10.99 & 0.13 & $0.13(12.12)$ & 2.38 & 10.82 \\
\hline
\end{tabular}

Table 2. Multiple linear regression on TSP and heavy metals concentrations and environmental factors. ${ }^{\star} \mathrm{p}<0.05 .{ }^{* \star}$ Standardization factor. ${ }^{* *}$ Non-standardization factor.

analysis of heavy metals, the regression model with three variates was statistically significant. Ventilation volume at a distance of $30 \mathrm{~cm}$ from the hood, machine operating time, and workload affected heavy metals concentrations. The most influential factor on heavy metals in the workplace was ventilation volume at a distance of $30 \mathrm{~cm}$ from the hood; heavy metals coefficient decreased by 0.93 as ventilation volume SD 1 increased. Heavy metals coefficient increased by 0.63 as machine operating time SD 1 increased, and workload SD 1 increased as the heavy metals coefficient increased by 0.13 .

\section{Discussion}

This workplace conducts work environment measurements conducted by external work environment measurement agencies twice a year. The agencies can evaluate intensive personal exposure, but cannot determine the primary cause of the occurrence of harmful substances. Most acids (hydrochloric acid, nitric acid, phosphoric acid, and hydrofluoric acid) were not detected. $\mathrm{Cr}$ (VI) was also not detected, but Ni, sulfuric acid, and sodium hydroxide were $0.001-0.003,0.021-0.035$ and $0.349-0.453 \mu \mathrm{g} / \mathrm{m}^{3}$. This study conducted a two-week measurement to reduce date variation to improve the limit of one-time work environment measurements.

Aspects of TSP and heavy metals in workplace. The exposure values of the anodizing and electroplating processes, which handle more heavy metals were higher. The concentrations of some types of heavy metals in all the processes were below the OEL of Korea; however, the Cr processes exceeded the OEL of Korea, which far exceeded the OEL of Korea $\left(\mathrm{Cr}(\mathrm{VI})=10 \mu \mathrm{g} / \mathrm{m}^{3}\right)$. Some $\mathrm{Zn}$ processes exceeded the OEL of Korea, whereas others had values close to those allowed in the working environment. The levels of $\mathrm{Pb}$ in anodizing and electroplating processes were higher than the OEL of Korea $\left(\mathrm{Pb}=50 \mu \mathrm{g} / \mathrm{m}^{3}\right)$. Cd, Al, and $\mathrm{Ba}$ did not exceed the OEL of Korea $\left(\mathrm{Cd}=10 \mu \mathrm{g} / \mathrm{m}^{3}, \mathrm{Al}(\right.$ fume $\left.)=5,000 \mu \mathrm{g} / \mathrm{m}^{3} . \mathrm{Ba}=500 \mu \mathrm{g} / \mathrm{m}^{3}\right)$. However, in the case of $\mathrm{Al}$, high concentrations were medium-sized and large-sized soft anodizing, and medium-sized and large-sized hard anodizing. Concentrations were also relatively high in coloring and sealing. The principal factor affecting the concentration was ventilation volume, following machine operation time and workload. The ventilation volume of the hood in the workplace was low; thus, the suction flow rate of the hood had to be improved.

According to Previous research, measured concentrations of TSP, $\mathrm{Cr}, \mathrm{Ni}, \mathrm{Cu}, \mathrm{Mn}, \mathrm{Co}$, and $\mathrm{Pb}$ in the metal finishing industry were $0.32 \pm 0.11,109.9 \mathrm{E}^{-6} \pm 38.4 \mathrm{E}^{-6}, 81.3 \mathrm{E}^{-6} \pm 89.5 \mathrm{E}^{-6}, 274.2 \mathrm{E}^{-6} \pm 118.4 \mathrm{E}^{-6}, 206.2 \mathrm{E}^{-6} \pm 173.4 \mathrm{E}^{-6}$, $73.3 \mathrm{E}^{-6} \pm 44.8 \mathrm{E}^{-6}$, and $69.9 \mathrm{E}^{-6} \pm 44.5 \mathrm{E}^{-6} \mathrm{mg} / \mathrm{m}^{3}$. Heavy metals concentrations were very low, whereas TSP levels were relatively high ${ }^{17}$. When checking the distribution of sample concentrations in $\mathrm{Cr}$ and $\mathrm{Cr}$ (VI) by samples for 10 plants $(\mathrm{n}=48)$, arithmetic mean $(\mathrm{AM})$ range of total and $\mathrm{Cr}(\mathrm{VI})$ concentrations were 0.89-523.7 and $0.09-113.2 \mu \mathrm{g} / \mathrm{m}^{3}$, respectively. Moreover, degreasing had the highest GM $21.6 \mu \mathrm{g} / \mathrm{m}^{3}$, followed by the plating process $\left(13.4 \mu \mathrm{g} / \mathrm{m}^{3}\right)$ and "other" process $\left(2.36 \mu \mathrm{g} / \mathrm{m}^{3}\right)$. Cr (VI) concentration with plating had the highest GM $\left(4.15 \mu \mathrm{g} / \mathrm{m}^{3}\right)$, followed by degreasing $\left(1.86 \mu \mathrm{g} / \mathrm{m}^{3}\right)$ and "other" process $\left(1.28 \mu \mathrm{g} / \mathrm{m}^{3}\right)$. Total Cr and Cr (VI) showed a high correlation of $0.91^{18}$. In the soil around the electroplating, $\mathrm{Cr}, \mathrm{Cu}, \mathrm{Pb}, \mathrm{Zn}$, and $\mathrm{Cd}$ were detected at concentrations of $22.7-453,9.51-120,18-108,24.1-143$, and $0.130-0.850 \mathrm{mg} / \mathrm{kg}$, respectively. Therefore, heavy metals in air can be detected at high concentrations in the surrounding environment for the electroplating plant $^{19}$. Individual samples were measured for $\mathrm{Ni}$ and $\mathrm{Cr}$ at three factories in the electroplating industry, and the concentrations in air and urine were checked. Arithmetic mean (AM) and Standard deviation(SD) of Ni and $\mathrm{Cr}$ were $7.4 \pm 6.4$ and $3.0 \pm 3.6 \mu \mathrm{g} / \mathrm{m}^{3}$ in the air. Additionally, creatinine concentrations were $30.1 \pm 19.5$ and $76.3 \pm 54.5 \mu \mathrm{g} / \mathrm{g}$ in urine. Individual exposure was not very high in air, and the correlation with urine concentrations was weak ${ }^{20}$. The factors influencing individual $\mathrm{Cr}$ concentration in $\mathrm{Cr}$ plating factories were confirmed by regression analysis. The exposure coefficients for wearing/not wearing gloves, smoking, and exposure after recently had a skin disease were $1.85,0.33$, and 0.45 , respectively. Washing hands before going to the bathroom reduced the $\mathrm{Cr}$ concentration coefficient to $-0.32^{21}$.

Particle size of heavy metals in surface treatment. At a metal finishing industry, PM2.5 of $\mathrm{Cr}, \mathrm{Ni}, \mathrm{Cu}$, $\mathrm{Mn}, \mathrm{Co}$, and $\mathrm{Pb}$ were $86.7 \mathrm{E}^{-6} \pm 17.3 \mathrm{E}^{-6}, 65.3 \mathrm{E}^{-6} \pm 88.9 \mathrm{E}^{-6}, 144.5 \mathrm{E}^{-6} \pm 143.6 \mathrm{E}^{-6}, 46.2 \mathrm{E}^{-6} \pm 25.8 \mathrm{E}^{-6}, 35.9 \mathrm{E}^{-6} \pm 22.0 \mathrm{E}^{-6}$, and $205.1 \mathrm{E}^{-6} \pm 95.1 \mathrm{E}^{-6}$, respectively. Additionally, $\mathrm{PM} 1 \mathrm{of} \mathrm{Cr}, \mathrm{Ni}, \mathrm{Cu}, \mathrm{Mn}, \mathrm{Co}$, and $\mathrm{Pb}$ were $73.2 \mathrm{E}^{-6} \pm 11.7 \mathrm{E}^{-6}, 55.7$ $\mathrm{E}^{-6} \pm 78.0 \mathrm{E}^{-6}, 102.1 \mathrm{E}^{-6} \pm 103.5 \mathrm{E}^{-6}, 39.6 \mathrm{E}^{-6} \pm 20.9 \mathrm{E}^{-6}, 23.8 \mathrm{E}^{-6} \pm 22.6 \mathrm{E}^{-6}$, and $161.6 \mathrm{E}^{-6} \pm 65.6 \mathrm{E}^{-6} \mathrm{mg} / \mathrm{m}^{3}$, respectively. Although smaller particle size resulted in lower concentration, the adverse effect on health was greater at smaller particle sizes. Additionally, finer particles can move the alveoli of the lungs ${ }^{17,22}$. The diameter distribution of $\mathrm{Cr}(\mathrm{VI})$ less than $10 \mu \mathrm{m}$ in the Cr plating plant was investigated, and the mass median diameters of $\mathrm{Cr}$ particles in the two electroplating tanks were $5.11 \mu \mathrm{m}$ and $6.38 \mu \mathrm{m}$, respectively. The $\mathrm{Cr}$ (VI) diameter distribution 
in the general manufacturing industry was $1.67 \mu \mathrm{m}$. Therefore, the electroplating tank had a relatively high mass distribution $^{23}$.

Limitations. The ventilation flow rate of the designed overall hood is $600 \mathrm{~m}^{3} / \mathrm{s}$. On the other hand, the ventilation flow rate of individual hoods is relatively low. In other words, it can be inferred that the hood or duct is poorly engineered or maintained due to aging. The reason why the deviation increased in high concentration level is because we mainly evaluated TSP. Large particles are measured due to leakage from the ventilation problem, and high outliers were observed.

Calculating the workload of the detailed process the precise amounts of chemical substances used in the electrolytes is difficult, because most materials are trade secrets. TSP was investigated in all the processes while making metal products. The quantitative composition of heavy metals particle size PM0.3 to PM10 using a realtime measuring instrument (Aerotrak Particle counter, TSI, USA) found that smaller particle sizes correlate to higher quantitative composition concentration in all the processes; among these, a higher quantitative composition concentration was measured as the particle size decreased in degreasing, Cr plating, and Ni plating ${ }^{24}$.

Checking the concentration of dust by particle size to provide information that can explain the extent of inhalation of smaller particles into the human body is necessary. A study for sampling nanoparticle size in electroplating revealed that the generation of nanoparticles were 64,327 particles $/ \mathrm{cm}^{3}$ with a passivating bath process and 33,249 particles $/ \mathrm{cm}^{3}$ without a passivating bath process based on $8 \mathrm{~h}$ TWA (Time-Weighted Average). Additionally, 5,645 and 4,947 particles/ $\mathrm{cm}^{3}$ were generated when working with and without the rotary abraser bath process, respectively. Thus, further research on nanoparticles is important ${ }^{25}$.

\section{Conclusions}

Most of the work environment measurement agency data at this workplace were undetected. Firstly, identifying the fundamental cause of the high concentration in the processes is difficult. Work environment measurement system is intensively focused on personal exposure. Obtaining a sufficient number of samples $\mathrm{N}$ of data is hard. Therefore, to confirm the reliability of work environment measurement system, conducting simultaneous personal and area exposure measurements would improve the results. suction flow rate was exceptionally low and difficult to collect when measured from a distance of $30 \mathrm{~cm}$.

The ventilation volume of the hood should be increased to make the total volume similar to $600 \mathrm{~m}^{3} / \mathrm{s}$. In addition, ventilation plans must be taken to reduce indoor pollutants by adding an external ventilation system. Therefore, improving the suction flow rate of the hood is necessary.Few studies have measured and evaluated exposure to TSP and heavy metals related to anodizing and electroplating. In this study, we have confirmed that the exceptionally high concentrations of TSP and heavy metals are primarily caused by low ventilation suction flow rates. Concentrations were similar among pre-treatment and anodizing processes, especially high in the $\mathrm{Cr}$ plating process, and primarily high in the coloring and polishing processes among the post-treatment process. Concentrations in other processes remained relatively high. Although in most processes, the $\mathrm{Al}$ concentration was the highest, $\mathrm{Cr}$ concentration was high in the $\mathrm{Cr}$ plating and polishing processes. This study provides data on the risk of exposure for anodizing and electroplating and improves the reliability of work environment measurement data, thereby improving health through the need for fundamental exposure. Since the amount of work was also different every day for each process, this showed a large variation for each sample. The reason why the ventilation amount differs for each process is primarily due to the size of the hood. The amount of ventilation may vary depending on the size of the hood. Secondly, because of the aging of the hood, foreign substances in the duct connected to the hood and foreign substances in the hood slot have been formed over a long period of use, but they have not been cleaned or maintained. It can be a data that can raise the problem of a one-time work environment measurement agency data. Room humidity, temperature, and product characteristics were predicted the variables affecting date concentration.

\section{Data availability}

Additional information associated with this article can be found in the supplementary data.

Received: 31 May 2021; Accepted: 20 October 2021

Published online: 18 November 2021

\section{References}

1. European Commission. Reference Document on Best Available Techniques (BAT) for the Surface Treatment of Metals and Plastics. Integrated Pollution Prevention and Control (IPPC), 1-582; https://eippcb.jrc.ec.europa.eu/reference/surface-treatment-metalsand-plastics (2006).

2. Wan, Y., Wang, H., Zhang, Y., Wang, X. \& Li, Y. Study on anodic oxidation and sealing of aluminum alloy. Int. J. Electrochem. Sci. 13, 2175-2185 (2018).

3. Krewski, D. et al. Human health risk assessment for aluminium, aluminium oxide, and aluminium hydroxide. J. Toxicol. Environ. Health Part B 10, 1-269. https://doi.org/10.1080/10937400701597766 (2007).

4. Vardar, F. \& Ünal, M. Aluminum toxicity and resistance in higher plants. Adv. Mol. Biol. 1, 1-12 (2007).

5. Kochian, L. V., Piñeros, M. A. \& Hoekenga, O. A. The physiology, genetics and molecular biology of plant aluminum resistance and toxicity. Plant Soil 274, 175-195 (2005).

6. Jaishankar, M., Tseten, T., Anbalagan, N., Mathew, B. B. \& Beeregowda, K. N. Toxicity, mechanism and health effects of some heavy metals. Interdiscip. Toxicol. 7, 60-72 (2014).

7. Hara, T., Hoshuyama, T., Takahashi, K., Delgermaa, V. \& Sorahan, T. Cancer risk among Japanese chromium platers, $1976-2003$. Scand. J. Work Environ. Health 36, 216-221 (2010).

8. Association Advancing Occupational and Environmental Health, American Conference of Gonvernmental Industrial Hygienists (ACGIH). Threshold Limit Values for Chemical Substances and Physical Agents \& Biological Exposure Indices. 1-150 (2019). 
9. Cherrie, J. W. et al. Prioritising action on occupational carcinogens in Europe: A socioeconomic and health impact assessment. Br. J. Cancer 117, 274-281 (2017).

10. International Agency for Research on Cancer (IARC). Chromium, nickel, and welding. IARC monographs on the evaluation of carcinogenic risks to humans; 49 (1990).

11. Shaw, L., Shaw, D., Hardisty, M., Britz-Mckibbin, P. \& Verma, D. K. Relationships between inhalable and total hexavalent chromium exposures in steel passivation welding and electroplating operations of Ontario. Int. J. Hygiene Environ. Health 230, 113601. https:// doi.org/10.1016/j.ijheh.2020.113601 (2020).

12. Bright, P. et al. Occupational asthma due to chrome and nickel electroplating. Thorax 52, 28-32 (1997).

13. Gabe D. R. Principles of Metals Surface Treatment and Protection; 2nd edition (ed. D. W. Hopkins.) 1-112 (Pergamon international library 28, 1978).

14. Kwolek, P. Hard anodic coatings on aluminum alloys. Adv. Manuf. Sci. Technol. 41, 35-46 (2017).

15. National Institute for Occupational Safety and Health (NIOSH). Manual of Analytical Methods 5 th Edition. https:// www.cdc.gov/ niosh/docs/2003-154/default.html (CDC, 2018).

16. United States Environmental Protection Agency (US EPA). Detection Limit/Quantitation Limit Summary Table. https://www.epa. gov/sites/production/files/201506/documents/mdlmql-toolbox-final-oct2010.pdf. (2010).

17. Onat, B., Çalışkan, N. S., Şahin, Ü. A. \& Uzun, B. Assessment of the health risk related to exposure to ultrafine, fine, and total particulates and metals in a metal finishing plant. Environ. Sci. Pollut. Res. 27, 4058-4066 (2020).

18. Yi, G. Y., Kim, B. \& Shin, Y. C. Worker exposure assessment on airborne total chromium and hexavalent chromium by process in electroplating factories. J. Korean Soc. Occup. Environ. Hygiene 25, 89-94 (2015).

19. Xiao, L. et al. Distribution and availability of heavy metals in soils near electroplating factories. Environ. Sci. Pollut. Res. 26, 22596-22610 (2019)

20. Chen, Y.-C. et al. Reliability and validity of expert assessment based on airborne and urinary measures of nickel and chromium exposure in the electroplating industry. J. Eposure Sci. Environ. Epidemiol. 24, 622-628 (2014).

21. Lumens, M. E. G. L., Ulenbelt, P., Géron, H. M. A. \& Herber, R. F. M. Hygienic behaviour in chromium plating industries. Int. Arch. Occup. Environ. Health 64, 509-514 (1993).

22. Zhang, Z. \& Kleinstreuer, C. Airflow structures and nano-particle deposition in a human upper airway model. J. Comput. Phys. 198, 178-210 (2004).

23. Kuo, H.-W., Lai, J.-S. \& Lin, T.-I. Concentration and size distribution of airborne hexavalent chromium in electroplating factories. Am. Ind. Hyg. Assoc. J. 58, 29-32 (1997).

24. Kirichenko, K. Y. et al. Complex study of air pollution in electroplating workshop. Sci. Rep. 10, 1-14 (2020).

25. Van Broekhuizen, P., Van Broekhuizen, F., Cornelissen, R. \& Reijnders, L. Workplace exposure to nanoparticles and the application of provisional nanoreference values in times of uncertain risks. J. Nanopart. Res. 14, 1-25 (2012).

\section{Acknowledgements}

This work was supported by the National Research Foundation of Korea(NRF) grant funded by the Korea government (Ministry of Science and ICT) (No. 2020R1A2C1007309) and the Ministry of Education of the Republic of Korea and the National Research Foundation of Korea (BK21 FOUR 5199990214126).

\section{Author contributions}

C.S.Y. conceived the idea and coordinated the research project. D.H.K. designed and conducted the experiments. D.H.K. and S.G.J. analyzed the data. All authors discussed the results. D.H.K., S.G.J. and C.S.Y. wrote the paper with input from all authors.

\section{Competing interests}

The authors declare no competing interests.

\section{Additional information}

Supplementary Information The online version contains supplementary material available at https://doi.org/ 10.1038/s41598-021-01577-9.

Correspondence and requests for materials should be addressed to C.Y.

Reprints and permissions information is available at www.nature.com/reprints.

Publisher's note Springer Nature remains neutral with regard to jurisdictional claims in published maps and institutional affiliations.

Open Access This article is licensed under a Creative Commons Attribution 4.0 International License, which permits use, sharing, adaptation, distribution and reproduction in any medium or format, as long as you give appropriate credit to the original author(s) and the source, provide a link to the Creative Commons licence, and indicate if changes were made. The images or other third party material in this article are included in the article's Creative Commons licence, unless indicated otherwise in a credit line to the material. If material is not included in the article's Creative Commons licence and your intended use is not permitted by statutory regulation or exceeds the permitted use, you will need to obtain permission directly from the copyright holder. To view a copy of this licence, visit http://creativecommons.org/licenses/by/4.0/.

(C) The Author(s) 2021 